\title{
Risky Sexual Behaviour among Students of Tertiary Institutions in South-South, Nigeria: A Qualitative Study
}

\author{
Eunice Osuala*, Basil Ogbu, Oluebube Udi \\ Department of Nursing Science, PAMO University of Medical Sciences, Port Harcourt, Nigeria \\ Email: *euniceosuala@yahoo.com
}

How to cite this paper: Osuala, E., Ogbu, B. and Udi, O. (2020) Risky Sexual Behaviour among Students of Tertiary Institutions in South-South, Nigeria: A Qualitative Study. Health, 12, 1095-1104.

https://doi.org/10.4236/health.2020.129080

Received: June 28, 2020

Accepted: September 5, 2020

Published: September 8, 2020

Copyright $\odot 2020$ by author(s) and Scientific Research Publishing Inc. This work is licensed under the Creative Commons Attribution International License (CC BY 4.0).

http://creativecommons.org/licenses/by/4.0/

\section{(c) (i) Open Access}

\begin{abstract}
Background: The prevalence and global trend of risky sexual behaviours are of concern due to its attendant health implications. Apparently, the social activities of teens and young adults predispose them to risky sexual behaviour than adults, as a result of peer pressure or influence. The prevalence and global trend of risky sexual behaviours are of concern due to its attendant health implications. The study was conducted in two tertiary institutions in Rivers State, Nigeria among sixteen (16) medical and nursing students of 100 and 200 levels within the ages of 16 and 22 years; eight (8) from each institution in September 2019. The two institutions are PAMO University of Medical Sciences and University of Port Harcourt, Rivers State, Nigeria. Aim: The study is aimed at eliciting information on awareness, knowledge, attitude and involvement in risky sexual behaviours amongst the students in tertiary institutions, South of Nigeria. Information is needed for a goal and result oriented intervention programme to curb the menace of risky sexual bebaviour. This motivated the researchers to adopt a qualitative study through which in-depth information on the matter could be harvested for an effective intervention. Materials and method: A Focus Group Discussion design was adopted for the study and consists of thirteen (13) open ended questions that guided the discussion. This was designed by the chief investigator and reviewed by experts in the field for the purpose of extracting relevant information from the participants. Purposeful sampling method was adopted to make sure age criteria and both sexes were equally represented. In-depth interview method was adopted to extract information from participants over two days. Information gathered was transcribed daily and summarized in themes based on objectives of the study. Result: The study revealed that the participants have good knowledge of what risky sexual behaviours mean as well as its conse-
\end{abstract}


quences. Majority, especially the females condemned the act even though there was carefree attitude towards risky sexual behavior as deduced from the study as participants affirm that the "pleasure in sexual relationship whether risky or not overrides the consequences". Majority of the participants affirmed to have been involved in a risky sexual behavior at one time or the other. Conclusion: Participants expressed thirst for information and remedies to reduce the incidence of risky sexual behaviours among young adults. The information gathered would guide an intervention programme to prevent and control risky sexual behavior which is considered of a public health importance.

\section{Keywords}

Risk, Sexual Behaviour, Youths, Tertiary Institution

\section{Background}

The foundation of any society is the youth. Students of tertiary institutions form part of this group and have the human right to exercise their sexuality. Awoke, Mekonnen, Daniel and Fantahun affirmed that neglecting the sexual and reproductive health of youths leads to high social and economic crisis [1]. The prevalence and global trend of risky sexual behaviours are of concern. This has become a focus of discussion with its attendant health implications. Apparently, the social activities of teens and young adults predispose them to risky sexual behaviour than adults due to peer pressure/influence. Understanding the determinants of risky sexual behaviour among students of tertiary institutions may contribute to the development of intervention strategies and policies aimed at improving their sexual behaviour. It is believed that university students are assets of a nation and potential agents to address the gap in the past and on whom the future national development and the entire generation is based. This fraction of the society is on the way of transforming to adulthood with great ambition. In developing countries where higher education is dramatically expanding, it is important to understand the force that influences youth education and how these forces interlink to the universities [2]. Globally, sexuality and sexual behaviors are of great concern with the age group of $15-24$ years [3]. There are a number of ways to define risky sexual behavior of youths. Glen-Spyron recorded the most widely used definition for risky sexual behaviour as unprotected vaginal, oral, or anal intercourse [4] while Center for Disease Control and prevention (CDC) defined risky sexual behavior as a behavior that increases one's risk of contracting Sexually Transmitted Infections (STIs) and experiencing unintended pregnancy [5]. The implication is that unless appropriate higher institution based interventions are established to curb the practice, certain behaviors and acts of the students can place them at greater risk of STI including HIV and unwanted pregnancy [4] [5]. There is therefore the need for information and 
awareness on the consequences of risky sexual behaviour amongst the youth as effective intervention depends on accurate information. The opinion and belief of the students is the most appropriate means to extract information from the youths on risky sexual behaviour; hence Focus Group Discussion (FGD), was adopted as most appropriate for this study.

\section{Materials and Method}

The study was conducted in two tertiary institutions in Rivers State, Nigeria among sixteen medical and nursing students of 100 and 200 levels. Two universities out of four in Rivers State (named A and B) were selected by balloting. A sample size of 220 students was selected from 491 using Yaro Yamanes sample size formula [6]. Proportionate sampling technique was used to recruit 146 medical students and 74 nursing students from the two institutions for the main (quantitative) study.

For this Focus Group Discussion, purposeful sampling method was adopted to make sure age criteria and both sexes were equally represented. Randomly, by balloting, sixteen (16) medical and nursing students of 100 and 200 levels were selected from the 220 students; eight (8) from each institution. There were four males and four females in each group from the two disciplines with ages between 16 and 22 years (Table 1). Population was guided by FGD principle on appropriate number. The FGD format consists of thirteen (13) open ended questions that guided the discussion, eliciting information on: awareness, knowledge, socio-cultural issues, attitude, practice as well as suggestions from participants on prevention of risky sexual behaviour. This was designed by the chief investigator and reviewed by experts in the field for the purpose of extracting relevant information from the participants. There were two sessions. The setting was the seminar room of each college. Two separate days served for the exercise with lecture period in consideration. Before commencement, informed consent was obtained from the University of Port Harcourt Ethical committee (Ref:

Table 1. Demographic data focus group discussion held at the department of nursing science on the $6^{\text {th }} \& 13^{\text {th }}$ of September 2019.

\begin{tabular}{cccccc}
\hline Participants & Gender & $\begin{array}{c}\text { Age } \\
\text { Group A }\end{array}$ & $\begin{array}{c}\text { Age } \\
\text { Group B }\end{array}$ & Discipline & $\begin{array}{c}\text { Level/Year of } \\
\text { study }\end{array}$ \\
\hline 1 & Male & 20 & 19 & Nursing & $100 \mathrm{~L}$ \\
3 & Male & 22 & 20 & Medicine \& Surgery & $100 \mathrm{~L}$ \\
4 & Female & 16 & 18 & Medicine \& Surgery & $100 \mathrm{~L}$ \\
5 & Female & 17 & 18 & Nursing Science & $100 \mathrm{~L}$ \\
6 & Male & 20 & 22 & Medicine \& Surgery & $200 \mathrm{~L}$ \\
7 & Female & 20 & 19 & Nursing Science & $200 \mathrm{~L}$ \\
8 & Male & 21 & 21 & Nursing Science & $200 \mathrm{~L}$ \\
\hline
\end{tabular}


UPH/CEREMAD/REC/MM61/025) as well as each participant. The semi structured interview guide was used to collect in-depth information on the participants' attitudinal and behavioral characteristics, opinion and beliefs concerning the risky sexual behavior on the two consecutive days in respective institutions. Each sitting lasted for approximately an hour. Researchers had two assistants; a recorder and a note taker, whose note taken were compared with audiotapes and transcribed on same day of event. Through the FGD sessions, the knowledge, perception and attitude to sexual risky behaviours among students was gathered. The perception of the students on predisposing factors, prevention, and consequences of sexual risky behaviours as well as attitude to the Sexually Transmitted Infections was elicited. The socio-cultural issues enshrined in sexual relationship in our communities were explored. Demographic data were coded and summarized under frequencies and percentages using SPSS software package, version 20. Recorded information was transcribed and summarized using proportions and themes based on investigated variables.

\section{Results}

Demographic data showed that the 16 participants comprised of 8 males and 8 females. All of them had West African School Certificate and were admitted into the institutions through Joint Admission Matriculation Board (100\%). Fourteen (87.5\%) were Christians while two (12.5\%) were Muslims (Figure 1). Only one (6.25\%) (Female) was married, while 15 (93.75\%) were single. Ages ranged from 16 to 22 years. Responses from participants were arranged in seven themes under subheadings based on investigated variables.

\section{Theme 1: Awareness}

Could there be any sexual relationship between two adults that can be termed risky? Both groups shouted "yes oo" Is the term "risky" only applied to a certain gender or age? There was a unanimous response "No" showing that they are aware that any man or woman can be involved in a risky sexual behavior irrespective of age. Have you heard of people engaging in what you may term risky sexual relationship? There was a little silence before one of the girls in Group I

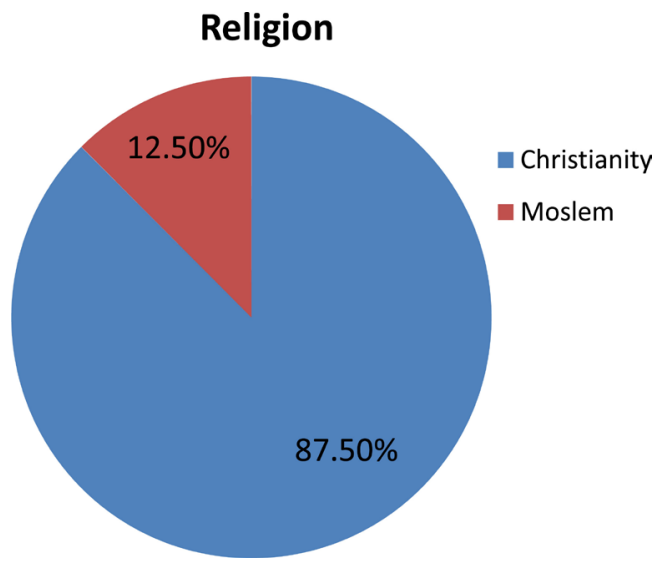

Figure 1. Religion of participants. 
affirmed with a nod and then went on to narrate how a close friend was lured into a gang rape by four students on a Nigerian campus in the pretense of "hanging out" for a birthday party.

\section{Theme 2: Knowledge}

What do you understand by the word risk and Risky Sexual Behaviours (RSBs)?

Participants described risk as something capable of causing harm while RSBs are sexual contacts that can result to harm. P1 (Participant) in group A said that "risk is something capable of causing harm" while P5 in Group B proffered the answer that RSBs are "sexual contacts that can cause harm".

Examples of RSBs were given by P7 "engaging in unprotected sex", P5 said that "RSBs is unprotected sex or intercourse without contraceptive or wrong use of contraceptive". What do you mean by wrong contraceptive? "use of high dose of quinine tablets, hot drinks(alcohol) or even insertion of herbs (names not known) into the vagina after "meeting" a man are employed by girls to prevent pregnancy". Can that also prevent STIs? "No! girls do not usually think of STI when having fun, we are only scarred of unwanted pregnancy". P4 said RSB includes partners getting involved in negative activities e.g. taking illicit drugs and all forms of vices in order to get sexual satisfaction. P2 mentioned multiple sexual partners. But he further mentioned that partners are free to have sex if they know their health status i.e. HIV status. P6 added masturbation as an example of RSBs. "Homosexuality is also an example". P8 shouted "No! and added that after all it is approved in America".

\section{Does RSB involve any consequences?}

In group A, P1 with the nodding of the head mentioned "STDs, pregnancy", while P3 concurred. In group B, P3 mentioned "unwanted pregnancy, loss of education". P5 exclaimed "RSBs becomes a habit and addiction if developed! even though it was not his turn to speak. P6 mentioned that there could be wide spread of STDs. P7 added abortion and death as a sequel. P4 mentioned increased population through "baby making factories" as some registered and unregistered outfits (homes) support the patronage of out of wedlock pregnancies. Is there any risk on the baby born out of RSBs? "Yes"! According to P4, "baby receives no or poor maternal care"!

\section{Is there any preventive measures against RSB?}

"Sure" was chorused in both groups. "Proper home training" was response from a participant in group A while "effective all inclusive family planning" was elicited from Group B.

Theme 3: Attitude: What is your feelings/opinion or belief about RSBs?

Attitude and perception of participants on the various questions were similar in both groups though some differences in opinion were elicited from the group aged 20 and above. The older students were of the opinion that the restrictions of males from female hostels and vice versa increase the zeal to have fun with the opposite sex at the slightest opportunity and meanwhile condom is not readily available on campus. "What do you expect us to do"? They asked. A participant 
in group B chipped in that "after all there are positive outcomes from RSBs". What are the positive outcomes of RSBs? Half of the participants opined that life is full of risk. P2 stated that "there are probabilities of harm but there are chances of being lucky (unable to get harm) with the practice". Sarcastically P8 in Group B said "early marriage and procreation is an advantage, after all the bible says increase and multiply"! Members of the group and even researcher burst out laughing. How do you feel/opinion about RSBs? Majority (3/4) however had negative attitude about the practice especially the female participants.

What are your personal opinions about RSBs among the youths?

In group A, P2 was of the view that even when people calculate the risk involved in RSBs, but the joy in the fun over rides the fear of the outcome of the risk. The men nodded while the girls smiled. In group B, P5 was of the opinion that it is too long a time waiting to have sex in marriage so people should get a particular partner whom they stick to for sexual fun before they get money to marry. "When do you get the money to marry when five years after graduation there is no job" chipped in P5. Do you believe that RSB can be avoided?

There was silence in both groups except for $\mathrm{P} 3$ in group A who broke the silence with "Yes it can be avoided if one is in Christ" Members of her group turned and looked at each other with a smile. None challenged her anyway.

Theme 4: Practice: Are youths involved in risky sexual behaviours? There was laughter in both groups. A male participant from group B, leaning back on his chair with head tilting to one side asked in a loud voice "Ma! You ask if youths are involved"? (Smiling) "Who then does it? Na we youths! We need fun and we dey do am anywhere anytime the opportunity comes, raincoat or no raincoat" referring to condom.

Do you think that many people within and outside your academic training institution involve in RSBs?

"Yes" was the chorus answer in group B. P1 in Group A said Yes oo. Do not mind our sister (referring to $\mathrm{P} 3$ in the Group). It is done even here in this our school. P2 said "Yes, many get involved in RSBs without considering the consequences".

In your view, what is the percentage estimate of people involved in RSBs?

Responses from Group A were as follows: P4 said 50\% practice RSBs and this is because of parental influence: some parents do all to protect their children from being involved in RSBs while religious influence adds to the restriction. P5 said that the percentage of people practicing RSBs is on the rise and that it is over $50 \%$. Another chipped in that in addition, as the Nigerian movies are mostly on romance and sexuality, the young people want to experiment on what they have seen or heard and this supports the rise in the practice. Group B response is thus: P8 in group B said about $90 \%$ of the youths are practicing RSBs. This is because of peer influence and what they see their friends do. P1 affirmed that it is not out of place to say that $90 \%$ of the youths practice RSBs as youths easily copy the lifestyle of their friends by getting more involved though some drop off 
the practice entirely, but this is rare. $\mathrm{P} 2$ was of the opinion that RSBs is not a practice that shows on the forehead so the practice may be on going without being noticed.

Do your colleagues take the risk?

Group B echoed "Yes!" but added that they will not mention names. In group A, P5 said that certain persons in the society don't engage in intercourse but some are involved in masturbation. P7 added that parental presence/influence stops many people from involving in RSBs but when youths are outside their homes they engage more often in RSBs.

Have you seen anyone with complications from RSBs?

"Yes", responded a female participant in group B, but that was in our secondary school era not here in the university. Some of my friends ended up with abortion which even became septic, sale of baby, child abandonment and dropout from school. The one raped in our year one is now socially withdrawn. And you were not involved? She shrugged her shoulders and snapping her index finger over her third finger, said "Tufiakwa" meaning God forbid!

How many times have you taken the risk?

Some of the participants agreed to been involved in the act. The female participants only smiled but six out of the eight (75\%) male participants admitted having taken the risk at one time or the other. The two that have not been involved in risky sexual behavior were from the private university.

Theme 5: Socio-cultural issues:

How does the society view sexual relationship among the youths or unmarried couples?

P6 in group A said "RSBs is not promoted or supported by the society". "The society condemns sexual relationship among the youths" "and unmarried young adults" retorted by P 8 in same group. P2 in group B said that the society sees sexual relationship among the young people as something that is detrimental.

What is the societal opinion about people engaging in RSBs? Societal opinion on the issue is biased. Is the approval based on a certain age, gender, status, poverty, social status, level of education? "It depends on gender many a time. Anything about sexual relationship in our society, the man is exonerated". Man is always right. It is expressed that it is the woman who opens the "door". "Society feels that there is an association between poverty and RSBs as young girls from low socioeconomic group tend to be sex hawkers. When the issue of RSBs is being addressed, the society focuses on the young adults as if age is immunity". It was deduced that level of education had nothing to do with the matter. Age, gender and poverty were therefore implicated in RSBs according to societal norms.

Theme 6: Reasons for RSBs

What do you think promotes risky sexual practice?

In Group A, P2 with a surprised look on his face stated that people practice RSBs in order to explore sexual life although such individuals are naïve. P6 men- 
tioned that economic challenge experienced by some people push them in that direction. Hence, they practice RSBs to earn money from their sexual partners. P5 mentioned that people feel the pleasure obtained from RSBs is more than the risk and some even make use of illicit drugs to enhance RSBs. Many nodded. P3 was of the view that peer pressure contributed to the increase rate of RSBs. In Group B, P1 was pleased to mention that sex is a normal phenomenon whether protected or not. P7 exclaimed in excitement that RSBs are practiced for recreational exercise!

Theme 7: Suggestions from participants on prevention of risky sexual behaviors:

What are your suggestions towards reduction of RSBs among youths?

Inputs from the two groups were similar except a participant in group B that felt he had something different. It was deduced from the two groups that recreational facilities should be provided in the society and schools to keep young people physically active as diversion therapy can reduce the urge for sexual act with fellow students. The need to scale up awareness programs on the risk of RSBs was suggested since curbing RSBs is a difficult task because the "bad eggs" influence the good ones to practice RSBs. It was also submitted that economic development and job creation/opportunity among youths would decrease the rate of RSBs. Suggestion on proper/correct sex education and parental guidance/counseling was made. This is because some parents feel that sex education is a no go area. P2 in Group B, with a grin on his face disagreed with the above suggestions from the others participants. He stated that he agreed the practice of RSBs is growing but it can only be curbed by:

- Community health screening to know self-health status in relation to STIs;

- Public health education;

- Availability and correct use of contraceptives;

- Removal of ban on visit to female hostel or room by male students;

- With emphasis, "contraceptives especially condom, like all other OTC drugs should be made available in school clinics and supplied on demand to reduce the rate of RSBs".

\section{Discussion}

University students (Higher School) are the focus in this study because the researchers also believe that sexual bebaviour among this group (youths) is of great concern [3]. The study revealed that the participants have good knowledge of what risky sexual behaviours means as well as its consequences. This is in line with the study by Awoke, Bogale, \& Hadgu [1]. That notwithstanding, the contribution from some participants that said partners are free to have sex if they know their HIV status portrays poor knowledge of Sex education because being HIV negative does not rule out other consequences of a risky sexual behavior. Majority, especially the females condemned the act even though there was carefree attitude towards risky sexual behavior as deduced from the study as the 
"pleasure in sexual relationship whether risky or not overrides the consequences". This was same with the study by Ajayi, Nwokocha, Akpan, Adeniyi, and Goon [7] in which participants generally condemned sexual risk-taking. This may be because the group studied and setting was similar. Majority of the participants affirmed to have been involved in a risky sexual behavior at one time or the other and a case of rape was even narrated. This is also in line with the cross-sectional study in Anambra State, Nigeria by Adinma, Umeononihu, Adinma and Eke [8]. The few participants that have not been involved in risky sexual behavior were those in private institution. This may be because their institution provides accommodation for students who are under the close watch of supervisors even after classes. With pornographic pictures, and psycho active substances; uncontrolled and easily accessible to youths, they may not always be in control of their actions hence when convicted of rape the individual' pleads it's the devil's hand work. Due to the alarming incidence of rape today, it has become a topical issue in Nigeria with the Assembly now in the process of enacting a law to punish offenders and protect victims. University students in South of Nigeria like their counterparts in the other parts of the world are exposed to a variety of risky sexual behaviours such as early sexual initiation, experiencing multiple sexual partners, unprotected sex, having sexual intercourse with the same sex, the use of substances like alcohol or drugs and involved in sex, having sex with older age partners and non-regular partners [3] [4]. Change in sexual behavior of this cohort will require multi-faceted strategies targeting socio-cultural norms and empowerment of women to develop skills in negotiating safe sex.

\section{Limitation}

One of the universities in the study is new and was at $200 \mathrm{~L}$ and researchers were limited to recruiting only participants within that level from the two universities. The findings also cannot be generalized due to small number of study population.

\section{Conclusion}

It is believed that university students are assets of a nation and potential agents to address the gap in the past and on whom the future national development and the entire generation is based. This group of society is on the way of transforming to adulthood with great ambition. Unless appropriate age and institution targeted interventions exist, certain behaviors and acts of the students can place them at greater risk of STI including HIV and unwanted pregnancy [4] [5]. Findings showed a thirst for information and remedies to reduce the incidence of sexual risky behaviours among young adults. The information gathered would guide an intervention programme to prevent and control risky sexual behavior which is considered of a public Health importance. Sex education in homes and schools is of paramount importance. Awareness on the consequences of risky 
sexual behavior should be scaled up while policies to control use of psycho active substances and pornographic pictures by youths should be put in place and enforced. National Universities Commission should make accommodation for all undergraduates - a prerequisite for accreditation of every university in Nigeria.

\section{Recommendation}

Sex education should be introduced at primary school curricular for proper and early orientation on healthy sexuality. Scaling up awareness on Maslow's Hierarchy of need for love and belonging may be emphasized.

\section{Conflicts of Interest}

The authors declare no conflicts of interest regarding the publication of this paper.

\section{References}

[1] Awoke, D., Mekonnen, A., Daniel, M. and Fantahun, B. (2016) Risky Sexual Behaviour and Associated Factors among Students of Debre Tabor University, Northwest Ethiopia: A Cross-Sectional Study. Ethiopia Journal of Health Development, 30, 11-18.

[2] Dennis, M., Peter, W., Marion, M. and Peter, N. (2012) Sexual Risky Behaviors among the Youth in Kenya. Medicine Science, 1, 177-187. https://doi.org/10.5455/medscience.2012.01.8019

[3] Alamrew, Z., Bedimo, M. and Azage, M. (2013) Risky Sexual Practices and Associated Factors for HIV/AIDS Infection among Private College Students in Bahir Dar City, Northwest Ethiopia. International Scholarly Research Notices, 2013, Article ID: 763051. https://doi.org/10.1155/2013/763051

[4] Glen-Spyron, C. Risky Sexual Behavior in Adolescence. https://www.bellavida.co.za/

[5] Center for Disease Control: Adolescent and School Health. Alcohol and Other Drug Use. https://www.cdc.gov/healthyyouth/data/topics/index.htm

[6] Yamane, T. (1973) Statistics and Introductory Analysis. Harpers \& Roy, New York.

[7] Ajayi, A.I., Nwokocha, E.E., Akpan, W., Adeniyi, O.V. and Goon, D.T. (2017). It's Sweet without Condom: Understanding Risky Sexual Behaviour Among Nigerian Female University Students. Online Journal of Health \& Allied Sciences, 16, 9. https://www.ojhas.org/issue64/2017-4-9.html

[8] Adinma, J.I., Umeononihu, O., Adinma, D.E. and Eke, N. (2016) Sexual Behaviour among Students in a Tertiary Educational Institution in Southeast Nigeria. Scientific Research Journal, 4, 87-92. 